\title{
Marine accidents: quality vs. safety and one step further
}

\section{Alexandros M. Goulielmos*}

Department of Maritime Studies, University of Piraeus, 80 Karaoli \& Dimitriou St., Piraeus 18534, Greece

E-mail: amg@aias.gr

${ }^{*}$ Corresponding author

\section{Kyriaki Mitroussi}

Cardiff Business School, Cardiff University, UK

E-mail: mitroussik@cardiff.ac.uk

\section{Androniki Gatzoli}

Department of Maritime Studies, University of Piraeus, Greece E-mail: Niki_Gatzoli@yahoo.gr

\begin{abstract}
We dealt with an essential issue- we believe- which is Quality vs. Safety in Shipping. Shipping is not proud for achieving zero defects or accidents, as it should. Efforts in the past-prior to 1998- for the industry to implement ISO 9000 failed and a full investigation is here made whether even the - for us-safety standard ISM Code- after 1998- will succeed. So, we have proposed a Total Safety Management philosophy, and a step further, which is a Safety Culture for ship's Manager (Captain). ISM Code regrettably failed to recognise the actual role of Captain and restricted itself to 'commitment on top'.
\end{abstract}

Keywords: Total Quality Management; TQM; total safety management; shipping; chaos and complexity; management; safety culture; marine captain; marine accidents.

Reference to this paper should be made as follows: Goulielmos, A.M., Mitroussi, K. and Gatzoli, A. (2008) 'Marine accidents: quality vs. safety and one step further', Int. J. Ocean Systems Management, Vol. 1, No. 1, pp.45-67.

Biographical notes: Alexandros $\mathrm{M}$. Goulielmos, $\mathrm{PhD}$ graduate of Brunel University (1974) with a thesis in Shipping Economics. Reader in Maritime Economics (1976-1979) at the University of Piraeus. Since 1992 Associate Professor at the Department of Maritime Studies and from 1998 full Professor in Marine Economics. Rich working experience in Banking (1970-1975, 1976), Shipping Finance (1975-1976), Shipbuilding (1976-1977, 1977-1979), Shipping as Dept. Manager (1977-1990) and Research (1975-today). 
In-charge of a Marine Insurance company. Since 1998 deals with Chaos and Complexity theory. In 1993-1995, General Secretary of Greek Shipping Ministry. Editor of IAME newsletter in the past. Author of 12 books and numerous papers in international scientific journals.

Kyriaki Mitroussi, holds the position of Lecturer (B). She was awarded her $\mathrm{PhD}$ in Management and Business from Cardiff University in 2001 and her broad research interests include third party ship management, shipping management, safety and quality in shipping, shipping economics and policy. Prior to her current post she served as an appointed lecturer at the University of Piraeus, Department of Maritime Studies in undergraduate and postgraduate degree programs. She has also worked with shipping companies while her research work has been published in international academic journals and in the international commercial and economic press.

Androniki Gatzoli is a Teaching and Research Assistant- in the Department of Maritime Studies (University of Piraeus) and a graduate of Economics. Holder of a $\mathrm{PhD}$ Degree of the same institution. She teaches transport economics, short Sea Shipping, Quality control in shipping, management of coastal and marine industries, and evaluation of investments in shipping. Her research interests are on issues of transport, short sea shipping and marine accidents. She has participated in many international conferences, in research studies and she has published papers in international scientific journals of the quality level of Maritime Policy and Management.

\section{Introduction}

Over the last decade or more, Quality, Safety and Environmental protection, as well security in shipping, have been improved. High-profile accidents, pressure from interested groups and a contemporary drive to improve the public image of shipping have led to the enactment of new safety legislation and the adoption of compulsory safety standards. The ISM Code, the quality standard ISO 9000/2001 14000, the OCIMF Tanker Management and Self-Assessment programme, the SIGTTO guide, and the ISPS Code have been applied in the industry within this context. The use of international and national laws, self-regulation and benchmarking are among the common management approaches that shipping companies have used as a response to this challenge and to implement safety management practices. Moreover, Safety Management Systems (SMSs) have been as high on the agenda of ship managers as they are on the agendas of managers in land-based industries.

Total Quality Management (TQM) is a widely known concept that appeared in the literature at the beginning of the 1950s and was first applied in Japan in 1980, and later in USA. This has long been celebrated, and was greatly popularised between 1990 and 2000. To be clear at the outset, in the context of TQM, quality in shipping is presented as:

$$
\begin{aligned}
& \text { "a ship management philosophy, for the Ship-owner and Captain, attempting to } \\
& \text { link ship service quality to charterers" satisfaction, by institutionalising } \\
& \text { planned and continuous quality improvement" (Cooper and Phillips, 1995, p.3). }
\end{aligned}
$$

This reflects only part of the ship-owning philosophy, especially when shipping quality is not being paid for. Therefore, in this paper, the authors have the opportunity to 
clarify what exactly quality is, and what is not, in general, and quality in shipping, in particular.

Moreover, SMSs are no more than compilations of standards, procedures and monitoring arrangements aimed at promoting the health and safety of people at work and protecting the public from work accidents (Osborne and Zairi, 1997). Obviously, quality alone cannot secure error-free and accident-free shipping operations. But even safety standards are not completely effective, as marine accidents ${ }^{1}$ unfortunately do occur, as shown in our empirical investigation. We believe that, for a complete analysis, one has to go a step further. Moreover, it is no accident that OCIMF and SIGTTO felt the need to go further than the ISM Code, i.e., towards self-assessment and other management tools (benchmarking/best practice, etc.) to complement quality. The all-inclusive nature of the code is indeed the very genius of those who drafted it, as the ISM code performs over the function of a legislative and regulatory umbrella, at the cost of overregulating an overregulated industry. Quality in shipping (ISO 9000/2001) is not compulsory and we believe that its adoption is rather a marketing tool and it is worth noting that ship owners do not readily adhere to non-compulsory quality, which is not covered by the freight rate. Traditional SMS (TrSMS) had limitations as they remained at a mere technical level and did not appear to produce an integrated approach to problems of safety.

As a result, a new, fast-growing and, we believe, timely concept, Total Safety Management (TSM), gained ground. This concept was first applied as a marketing tool over a decade or so ago, with an emphasis on safety features of motor vehicles (such as airbags). ${ }^{2}$ Nowadays, TSM has developed into a management philosophy in its own right. Having originated from an integration of safety management practices with TQM, the TSM approach can be seen now to be only partly related to TQM, and even to complement and eventually to substitute it. TSM processes and principles, which share certain common objectives with TQM, focus on safety bringing about changes in quality - as TQM does - but deliver improvements in all areas of an organisation's functioning including quality (Cooper and Phillips, 1995). TSM focuses primarily on the accident causation chain in an attempt to prevent the occurrence of accidents or near-miss incidents.

This focus obviously satisfies IMO better, as well as other statutory bodies, charterers and environmentalists. With respect to the TSM approach, we will deal here primarily with the ISM Code, ${ }^{3}$ which is a "safety and environmental-protection standard", and only touch on the ISPS Code, ${ }^{4}$ and the OCIMF $^{5}$ and SIGTTO $^{6}$ guides. We will start by presenting some general conclusions that apply to both the ISM Code and the ISPS Code: ${ }^{7}$ these two codes are certainly based on current principles of management and organisation science, and have a number of important provisions.

First, to comply with the ISPS Code, risk assessment of each vessel is required for security, as is the appointment of a security officer (CSO) with some ten functions. Empirical research has shown that half of all DPAs are also CSOs. Although this may be convenient, it sounds as though insufficient attention is being paid to the subject of security, which may be even more serious than safety, as now the prime consideration in business is not health any more but security. The requirements of the ISPS Code are shown graphically in Figure 1. 
Figure 1 Targets of ISPS code

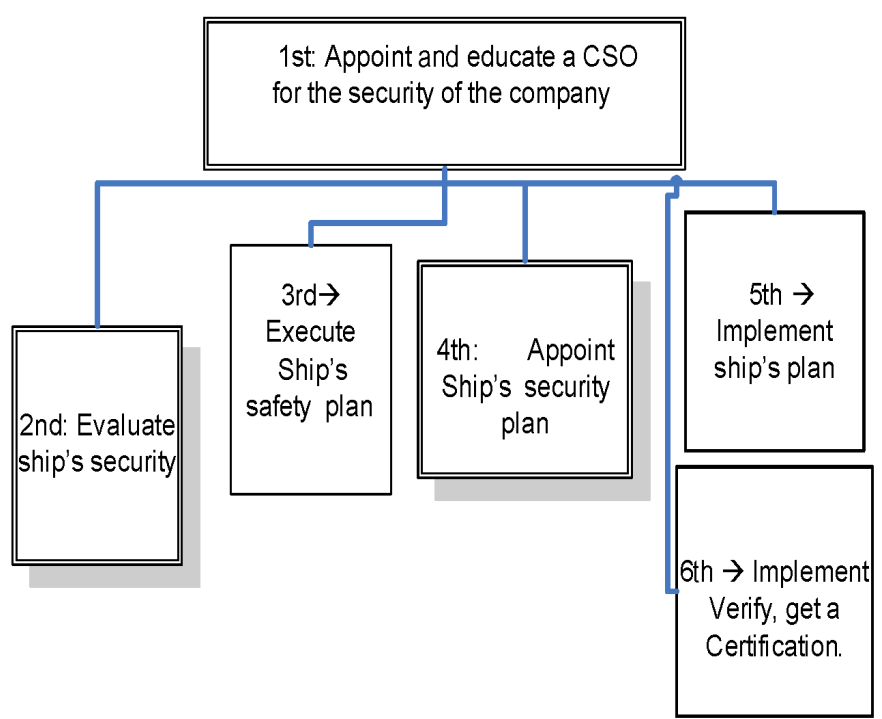

Source: ISPS Code. Goulielmos and Anastasakos (2005)

So, the ISPS code is totally different from the ISM Code, though the former is an essential prerequisite of the latter. The former ought to receive attention in its own right, and it was not right to throw responsibility for it on the shoulders of the safety people. This is also shown in the safety manuals.

Now is also the time when the international shipping community of Europe contemplates using the penal code against crew members to prevent pollution (Urrutia, 2006). Will this be effective? Or will good sea officers soon prefer other employment?

\section{The aim of the paper}

The aim of this paper is to critically review the concept of TQM, in general, and in the context of shipping, in particular, and propose an alternative management philosophy and practice, i.e., that of TSM for shipping companies and IMO. A relevant investigation into approximately 50 contemporary marine accidents has been carried out to see whether marine accidents still do occur and why. The role of top management and of human error ${ }^{8}$ has been assumed to be very important for safety or even for self-assessment, and this may be quite logical. The basic assumption of commitment from the top, on which the whole ISM code rests, must be most carefully examined, as it is in this paper. We have introduced the concept of 'safety culture' and we argue that it is the responsibility of the Captain to establish it on board.

\section{The structure of the paper}

In the first section, a literature review and a thorough critique of the TQM philosophy are presented. Next, the analysis section presents total safety management - TSM - in detail 
and its advantages are outlined. The proposal that TSM represents an effective alternative to the dominant philosophy of management in the shipping industry is advanced, with supporting arguments. The next section addresses the issues of TSM implementation within the ISM Code system and beyond. Safety culture is here proposed as a system for on-board implementation. Finally, in the last section, empirical evidence is presented, followed by final conclusions.

\section{Literature review and criticism of TQM}

\subsection{Complexity theory and TQM}

Priesmeyer (1992) (Algera, 1990, pp.154, 155) argued that TQM is simply a philosophy and a management system calling for personnel participation with a focus on continuous improvements in quality by relying on empowerment, an idea advanced in 1979 and 1980, which has not yet passed on to Captains and ship crews.

McMaster (1996, p.129) stated that TQM initiatives made an exciting and promising start, but unfortunately later became a bureaucratic burden. This may also be the case with the ISM code. Moreover, a CEO raised the question (McMaster, 1996, p.129): "Why do all our initiatives for quality begin to lose effectiveness?" The initial interest comes from both new ideas and actions, but in fact there is a failure to devote the necessary time prior to the inception of the initiative to develop an understanding of the process. Moreover, the cultivation of ways to sustain the development of that understanding is neglected.

\subsection{A further thorough critique of TQM}

\subsubsection{Introduction}

TQM is further criticised in the literature for creating, or relating to, at least five serious problems, as illustrated in Figure 2.

Figure 2 Problems related to TQM

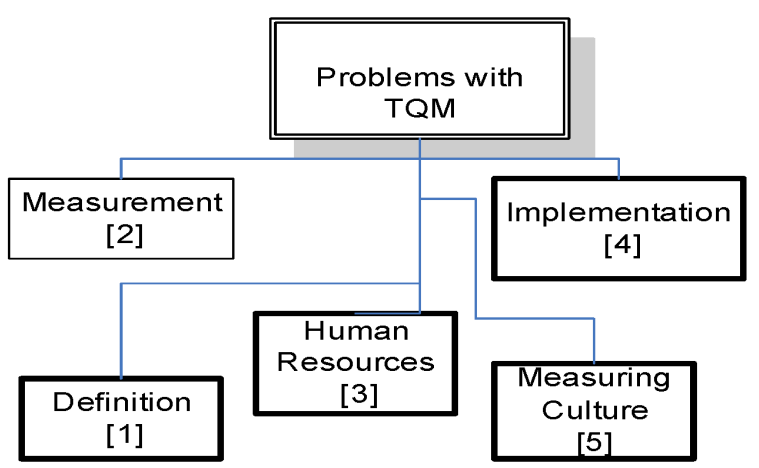

Source: Adapted from Cooper and Phillips (1995) 


\subsubsection{Quality definition}

A shipping manager studying TQM will be surely confused by the many different definitions used to define TQM: for Crosby (1979), TQM is conformity to requirements, while for Juran (1979), it is fitness for use; Deming (1986) stated that this is a predictable degree of uniformity and dependability at low cost, suited to the market; Feigenbaum (1983) argued that quality is a moving target defined by the customer; Collard (1989) thought of it as a situation with zero defects; ISO 8402 stated it as "the totality of features and characteristics of a product or service that bear upon its ability to satisfy stated or implied needs" and Margaret Thatcher described it as "having customers who do come back and products that do not". More important is the fact that emphasis is sometimes given to functional quality and sometimes to technical quality. Hill (1991) divided correctly quality into two aspects:

- product aspects

- process aspects.

First, quality of design is required, and this is defined as conformance to the requirements of the user. Then, for the process, TQM assumes that quality is the outcome of all activities and all functions and all employees must take part.

This means for shipping that the ship is, par excellence, a place where quality has to be 'produced' and thus, the total crew must take part.

\subsubsection{Quality measurement and feedback}

Botterill (1991) argued that the most difficult as well as the most crucial aspect of TQM is to measure quality. A good shipping manager requires regular feedback, a tool of managing of the utmost importance. As Algera (1990) argued, information feedback is a necessary component for the effective functioning of any system to prevent entropy and exert adaptation. Feedback in shipping, however, has to be re-organised from what it is (voluntary, negative and depending on the time availability of the First Mate) to positive, following a "reporting culture' and being a full-time effort.

Feedback must be positive (Battram, 1998, p.158). In shipping, feedback being negative and causing corrective or even disciplinary actions may be a disincentive. More tragic still is the statement of SIGTTO:

"The written procedures may be excellent, and fully compliant with the code, but if they are not reflected in practice aboard the ship, the SMS does not comply with the Code" (SIGTTO, 2001, p.20).

So, a 'safety culture' must be first established. The safety culture of the ship is the product of individual and crew values, attitudes, competencies and patterns of behaviour that determine the commitment to, and the style and proficiency of, the ship's health and safety programmes. Ships with a positive safety culture are characterised by communications founded on mutual trust, by shared perceptions of the importance of safety, and by confidence in the efficacy of preventive measures.

Negative feedback, however, is the whole philosophy of the ISM Code. If you ask ten system designers to design a quality standard, $80 \%$ of them will design it with some form of negative feedback or equilibrium. Thus, the ISM Code established negative feedback by the compulsory spotting of non-conformities. ${ }^{10}$ This is the heart of the system, as one 
is required to document all non-conformities: ${ }^{11}$ minor or major. Indeed, the ISM Code, unaware of complexity and chaos theory, did not introduce either positive feedback ${ }^{12}$ or a proper communication system (Goulielmos, 2002; Goulielmos and Giziakis, 2002; Goulielmos-Goulielmos, 2005). These are two important defects that have to be remedied.

This, however, presupposes that the vessel is a system of automatic self-correction. As the vessel is not, then, as Katz and Kahn (1966) argued in a different context, the process of attending to, interpreting, and acting on, the feedback is even more crucial. Shipping is a situation where the roles of Captain, DPA ${ }^{13}$ and Management are dominant. But, imagine the shipping manager, the Captain and the DPA making choices about how to interpret feedback and only allowing certain sorts of non-conformities (or 'complaints') ${ }^{14}$ to be 'heard', and thus, acted on, while others may be dismissed or ignored as irrelevant. This is clearly very important. Finally, TQM faces difficulties in developing reliable, objective measures of quality owing to its subjective nature (Cooper and Phillips, 1995, p.4).

As Priesmeyer (1992, pp.141-144) argued, chaos theory offers a simpler understanding than that of "TQM statistical process control" to increase the precision and sophistication of quality control. The former always takes the form of a change to the system and changes in the system's behaviour, which are of course measured. Moreover, 'phase planes' (changes worked out in all four quadrants of the classical Cartesian chart) can be used to examine sensitively the behaviour of a single measure over time, thereby offering a simple, more efficient, substitute for traditional statistical quality-control charts.

\subsubsection{The human element/human resources in quality}

\subsubsection{Introduction}

TQM ignored human resource perceptions, attitudes, commitments and culture changes, within a company, because it focused the attention of managers on production, as Wilkinson et al. (1991) argued. In shipping, this means that focus should be on the vessel, as this is the place of production. Oakland (1989) stated that TQM tried to make everyone accountable for their own performance and to get them committed to attaining quality in a highly motivated fashion. As Goulielmos (2002) and Goulielmos and Giziakis (2002) argued, accountability and commitment are much weaker attitudes to safety than responsibility and it is with regard to this point that the ISM Code has to change. The ISM Code puts emphasis only on commitment and especially commitment from top management. But, top management is absent from production, i.e., on board the ship. That is why a commitment from the Captain is also required and has to be established, as proposed in this paper.

\subsubsection{Motivation for quality}

Oakland (1989) brought in motivation theories to attain quality. In fact, the ISM Code gives some hints that Captains must motivate the crew in the observation of safety and environmental-protection policy. This means that the Captain must persuade the crew to adopt attitudes and procedures. This implies a futile motivation, perhaps even without moral reward. This has to be re-examined. 


\subsubsection{Quality culture change: communication and dialogue}

As Seddon (1989) and Goulielmos and Giziakis (2005) have argued:

- many TQM programmes failed because they did not achieve 'culture change' (Schein, 1999; Goulielmos, 2005) ${ }^{15}$ related to the underlying values and behaviour of employees

- $\quad$ in the case of the accident of M/V 'Herald of Free Enterprise' (Goulielmos and Goulielmos, 2005) and M/V 'Samina Express', communications and dialogues were ineffective or absent.

The ISM Code demands an extra effort from shipping managers, Captains, DPAs and office personnel, but with no reference to any kind of specific motivation. This omission can be regarded as the beginning of a failure process, as leadership without motivation will not be effective for safety. As far as communication is concerned, the ISM Code only requires the company to ensure that the crew has a working language(s) to be understood and for the crew to communicate effectively. The why, the how, the when and the what in communication are left out. This we believe is a serious mistake.

\subsubsection{Management commitment from on top for quality}

Important evidence against TQM is provided by Atkinson (1990), where he argued that $80 \%$ of all TQM initiatives in UK failed to fulfil their potential. A lack of senior management commitment to the quality process is the common fault. The ISM Code includes a similar mechanism described as 'commitment from top'. Many managers do not view themselves as part of the quality problem, but think that quality is a 'workers' motivation issue'. This is even more so where managers see the Captain within the ship as responsible. Crucial infrastructure is missing in quality programmes (Weick and Sutcliffe, 2001, p.82) and companies do not adjust their routine quality-control practices to deal with more complex, emergent problems (Sitkin et al., 1994). The ISM Code brought in company responsibility to secure the necessary resources for safety for the Captain.

In effect, scientists (Hackman and Wageman, 1995, p.81) recognised efforts by companies to embrace the quality movement as the beginning of a broader interest in reliability and mindfulness, but quality programmes have led to only modest gains owing to incomplete adoption.

\subsubsection{Quality implementation}

Many TQM failures are also related to uncertainty about how to implement quality improvement programmes, because senior management lacks an understanding of the fundamental principles of TQM and the way it can best be applied in practice (Dale and Plunkett, 1990).

\subsubsection{Time scale and resistance to change: quality in mergers and crisis}

Usually TQM is rejected when it is used as a vehicle for cost-reduction and/or for downsizing, and this is important too for shipping. Resistance to change is another important cause of failure, because TQM is conceived as a threat to existing power bases (Hellriegal et al., 1989). Quality may also be lost after mergers and service crises 
(1998 annual report, e.g., for Union Pacific; Business Week, 6 October 1997). Moreover, a lack of appreciation of the time scale is involved (Botterill, 1991), as the completion of initial 'awareness building' quality projects usually take from 12 to 18 months.

\subsubsection{Quality culture}

Long-term efforts are made within the companies to develop a quality culture. But how can we define quality culture? In a culture for quality, high-trust social relationships and respect for individuals and a shared sense of membership of the organisation, and a belief that continuous improvement is for the common good (Hill, 1991) are nurtured. The ship must become 'our' ship and the company 'our' company. For those knowing the society of a ship, this is most difficult because crew members come and go frequently (Goulielmos-Goulielmos, 2005). Also, the problem with this and all similar definitions is that it is impossible to translate it into action (Cooper and Phillips, 1995).

\subsubsection{Resistance to TQM vs. integration}

A number of authors have argued that TQM could be applied to the practices of safety (Blair, 1996; Rine, 1994; Pollock, 1995). Other authors have argued that TQM should be completely rejected (Manzella, 1997). However, even if one sees TSM as an integration of safety with the essential ingredients of TQM, which reflects the origins of the concept of TSM, TSM however involves a further step. There are common concepts and no doubt objectives in TQM and TSM:

- attainment of accident prevention

- organisational commitment

- use of systems for measuring and communication

- $\quad$ embedding of a safety culture

- $\quad$ satisfaction of customer/charterer

- the requirement for continuous improvement.

\subsubsection{A final remark}

However, and despite the similarities acknowledged in the process and techniques involved, for us, striving for safety and striving for quality are certainly not the same thing. This is the message of this paper. Having 'injected' safety management with the values and practices of TQM, scholars and practitioners have produced a much-improved version of a management approach, i.e., that of TSM. Can TSM respond more effectively to the above problems? We next turn our attention to this fundamental question.

\section{Analysis: total safety management}

\subsection{Introduction to TSM}

It is argued that TSM provides "a focus on safety and offers a realistic way forward at less cost and confusion" (Cooper and Phillips, 1995, p.8). "Safety is a great analogy for 
understanding quality". "Everything safety is about relates to the absolutes of quality management" (Ezell, 1992, p.152) ${ }^{16}$ But quality does not axiomatically result in safety.

In addition, we expect employees to get more job satisfaction and have increased commitment to the shipping company with TSM (in another context, see Drapkin, 1980). TSM is thought to produce improvements in all areas of an organisation's functioning, including quality (Cooper and Phillips, 1995). TSM must be used as an agent for organisational change and for development (Crosby 1989 cited in Ezell 1992, p.152). The effectiveness of services must be determined by their safety aspects. For instance, naval architects have to be asked to review their designs, the materials used ${ }^{17}$ and their reliability, and even to concern themselves with whether relevant repair facilities are available or not. TSM aims at a significant reduction of accidents through efficiency and effectiveness of ship operations.

\subsection{Safety and productivity}

Any conflict between safety and productivity can be eliminated by optimising the workflow involved on board (in a different context, see CBI, 1990). Here, opportunities are provided to reduce role ambiguity and job stress. Also, Cooper and Phillips's (1995, p.4) argued that improvements will be realised in quality and reliability of service, competitiveness and profitability (Williams, 1991) (for shipping this means delivery of transported cargo as agreed, safely and without loss - part or whole - with no robbery, alteration, contamination, breakdown or pollution).

\subsection{Proactive philosophy with TSM}

TSM, as noted earlier, is a management philosophy that focuses on prevention of accidents or near-miss incidents; it is a practice centred on taking a proactive approach for long absent in shipping. This is normally achieved by:

- establishing and adhering to rules, regulations and instructions

- setting up clear lines of responsibility

- two-way communications

- ensuring that hazards and risks are identified and assessed

- providing monitoring and review of the safety performance (Cooper and Phillips, 1995).

The ISM Code has adopted this list, but not responsibility and open-access communications.

\subsection{A deeper insight into TSM}

\subsubsection{Introduction}

TSM must make safety as a core value in the organisation and the safety system must be an integral part of business. Safety must be a determining consideration in decision-making. Employees and management have always to take into account how a decision will affect the aim of accident-free operations. The focus should be on 
creating a safety-oriented culture, where everyone in the company accepts and acts in a safe manner and strives to make improvements to the safety environment.

\subsubsection{Traditional Safety Management (TrSM) vs. TSM}

TSM is quite distant from the traditional focus of safety management where the company only acts when accidents occur (Goulielmos-Goulielmos, 2005). In fact, it has been found that traditional compliance-oriented programmes do not always improve the safety results, because they concentrate on mere technical requirements and on obtaining short-term results (Weinstein, 1996). Technical requirements mandated by regulations and industry standards are too narrowly focused and lack momentum for continuous improvement. In addition, TrSM programmes are not integrated throughout the organisation, hindering safety communication and internal learning as well as the development of a common safety management approach.

This means that a change in safety management practices is required. Moreover, such a change would entail:

- moving away from the inspection-correction model (ISM Code) to a proactive partnership among all involved

- moving from viewing safety as the exclusive responsibility of the DPA, to making sure that everyone, from top management to Captain, crew and office personnel, are involved in the topics and process of safety.

Safety in shipping is seen nowadays to have been reduced to the notion of inspecting premises - the company and the vessel - and generating lists of compliance recommendations. These tasks have been restricted by putting them in the job description of the DPA and the First Mate.

Given the experience from other on-shore industries, where safety has historically been regarded as a compliance issue with management deciding and employees following instructions (the Newton paradigm), safety seems to have been kept separate from regular management in shipping, too.

The role of shipping executive is not only to sign the safety and environmental-protection policy ${ }^{18}$ in safety manuals (see next part), but more importantly to provide safety leadership; and see that the safety system underpins the totality of the organisation and the vessel. The degree to which the ISM Code caters for all that is a question of practical value.

So, what does a change in the traditional safety paradigm entail? It is a change facilitated by safety management.

\subsection{Advantages of TSM}

\subsubsection{In relation to definition}

Contrary to the confusion that the concept 'quality' has created with regard to its definition, safety entails no such perplexity, as it is a straightforward and objective matter in the minds of most people. In addition, a common framework of reference already exists based on the regulatory framework that is in operation both at national and international level. This enables people not only within the same company, but also across organisations and even countries, to 'speak the same language' when it comes to 
safety. This in itself is particularly important for shipping, which is an international business, where players must have a common reference point, a norm against which to benchmark.

\subsubsection{In relation to measurement: a theoretical approach}

Coming to safety measurement in ships, every task, job or operation has to be objectively analysed in terms of:

- risk

- duties

- responsibilities

- impact on other ship's functions.

Written procedures and method statements have to be used as standards by which performance is objectively measured and assessed. This is what the ISM Code refers to as "safe working practices and safe working place on board". Moreover, the significance of each task or process for the safe and effective functioning of the overall operating system must be ascertained in relation to all other tasks as a whole. We believe that in the end, the ISM Code could be greatly improved if an 'expert system' (knowledge-based system) was available on board.

Changes in workstations, work practices and design procedures should be driven from their impact on safety and synthesised with operational requirements. Every aspect of the ship and of the company has to be subjected to rigorous objective scrutiny, significantly contributing to the overall effectiveness of the ship and company, while also satisfying IMO requirements and those of other legislative bodies.

Day-to-day performance has to be objectively monitored in all departments of the ship. Any deviations from the established performance standards (as required by the ISM Code) should be rapidly identified and corrected before much cost and harm occurs. However, this must be organised beforehand.

TSM may achieve:

- reductions or eliminations of perceived conflict between productivity and safety, as mentioned earlier

- reduction in operating and accident costs

- protection of personnel from harm

- promotion of an identifiable safety culture.

The ISM Code indeed cares about human injury or loss of life, as reducing these are among its stated objectives. The proper approach is not adopted by the ISM Code, however, to the transformation of the vessel from what it is to a "knowledge centre/unit or organisation". Marine accidents can only be prevented by the 'implicit' knowledge that in the past has effectively prevented accidents, and this is not contained in the books or manuals. Best practice creates a hope, but in 'knowledge' there is more than hope. 


\subsubsection{In relation to feedback}

The tools and systems used to provide feedback to both individuals and to the ship have to be concerned with both technical and human resource aspects of performance, as has been argued by Wilkinson (1992) in a different context. In TSM, we need routine information related to deviations from established safety performance standards on the part of diverse functions and this must definitely include human resources and maintenance. Feedback is a crucial requirement and is the company's responsibility, but depends on the will of the crew and on instructions to ensure that information reaches the Second Mate in a timely manner, so that he or she can conduct the audit of the safety system. We know that the time devoted to the operation of the ISM Code in a vessel is only 2 hs per day. What is more, motivation to report accurately (a reporting culture) is absent. Maintenance is indeed within the ISM Code's requirements, as described in its Section 8. Lack of space prevents us from developing further this theme of the so-called 'reporting culture"19 (Weick and Sutcliffe, 2001, p.129), even though we consider its cultivation to be essential.

\subsubsection{The ship's safety culture}

The most difficult part of all is to create a Ship Safety Culture when there is rapid turnover of the ship's crew. Can a culture be developed in the ship in spite of the change of personnel? Borrowing from Turner and Pidgeon (1997), the effectiveness of the ship's culture rests on whether the crew acts in a concerted way when facing a problem, and with sufficient similarity on three accounts: approach, outlook, and priorities. This has to come to be a collective and sustained response in the face of problems. But inspiration has to be provided for a sufficient time to achieve similarity. Here, the raw materials that need to be held in common are: the shared values, norms and perceptions (Turner and Pidgeon, 1997, p.102). Moreover, Crew and office personnel are never together for long periods, sometimes not even for short periods. It seems that Management can only deal effectively with the office culture because there is a long distance between office and ship. Thus, the recipe for success is that the beliefs, values and actions, and preference for safety among top managers are communicated credibly, consistently and saliently to Captain and from him on to the Crew. This must be so as the Captain's culture can be received consistently and felt strongly by the majority of the people on the ship. But do things actually happen in this way? The effort is normally limited to a simple statement in the safety manual, as will be discussed later.

\subsubsection{The subjective nature of the concepts}

Much of the confusion around TQM measurement and implementation can be attributed to the subjective nature of the concept of quality and a lack of understanding of what quality is. As already argued, safe working practices make much more sense to the crew than some abstract notion of quality imposed from above. On top of that, unlike quality, safety is being underpinned by statutory legislation and as a result TSM is at an advantage in that it can build on what already exists. 


\subsubsection{The safety culture}

It is far easier to build on an existing - even if only underlying - safety culture, than to create a new quality culture from scratch. Commenting further on this concept of safety culture, we would argue that 'Safety Culture' is synonymous with 'mindfulness culture' (Weick and Sutcliffe, 2001). This last concept entered public awareness through the vocabulary of Nuclear Safety after the Chernobyl nuclear power plant explosion and subsequently spread quickly to the commercial aviation and chemical processing industries. Moreover, it also features prominently in published and commercial reports on the high incidence of 'adverse medical events' in the health ${ }^{20}$ and care systems (Kohn et al., 1999).

Reason has defined 'safety culture' (Reason, 1997, pp.194, 192-222, 294). However, we would place a greater emphasis upon the role of open lines of communication for safety, as found in Xerox's paradigm.

It needs to be noted, however, that all treatments of safety ignore the fact that in shipping, management is done from a distance, and the safety culture of Captain must (or must be made to) coincide with that of management. In the area of the Captain's safety culture and how this harmonises with that of top management, nothing has been written so far. We hope to deal with this in the next section of this paper.

\section{Implementation of TSM}

\subsection{The OCIMF guide}

The OCIMF Guide (2004) is an initiative from the tanker industry to complement the ISM Code. Moreover, it is designed to fill a possible gap between the ISM Code as it has been identified in our criticism. The guide, called a quality standard, is a further tool to promote safety, as operators normally ignore the level of safety they have reached and thus, they do not try to improve it. Usually, the standards, if followed, provide the basics, i.e., the minimum. Also tanker operators know the requirements of the oil industry. ${ }^{21}$ This guide is a more effective tool than the ISM Code, as it gives a stronger role for a charter party. The TMSAP ${ }^{22}$ is a tool that can help the ship's managers/operators to measure and to improve their management systems. For this purpose, lists have been worked out with 'key performance indicators' and with 'best practice'. ${ }^{23}$ The programme encourages the managers to evaluate the SMS at the outset. At the end, companies have to transfer the best practices to all ships - which we welcome as a positive move - through the consistent application of improved procedures, etc. The results from these self-assessments - for this is all what it is - can be modified into a plan with stages that improve safety and environmental performance. The TMSAP simply provides direction $^{24}$ and builds on the ISM Code and provides a feedback of information to the charterer about the effectiveness of the SMS of the ship manager. Given that this introduces a uniform approach towards the collection of information, it eliminates the possible overlap of efforts from one ship to the other on the part of the ship managers. The TMSAP is based on the belief that it encourages ship managers to achieve high standards of ship management and of continuous improvement, and it provides direction towards the proposal of current best practice for the industry via the forum. The key stages here are four: plan, act, measure and improve. 


\subsection{Variations in TSM policies}

There are various theories of TSM and we will add our own. Cooper and Phillips (1995) argued that TSM is normally achieved by formalising and adhering to a coherent safety policy (as set out in Figure 3).

The ISM Code requires plans and lines of responsibility but through the usual organisation charts. In safety manuals, companies even provide job descriptions for the Crew. On communications, however, the scene is unclear, as the code requires only 'a common language', which is an essential first step. The Code requires knowing the hazards and risks. Monitoring is required by the Code through reporting and checklists filled out by Chief Officer in practice. What is then missing?

Figure 3 Safety policy in TSM

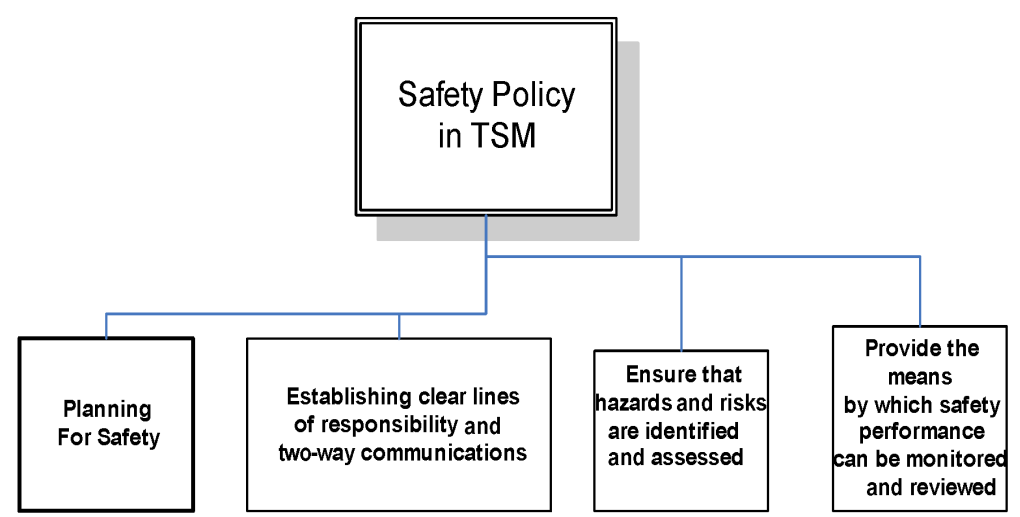

Source: Adapted from Cooper and Phillips (1995)

Goetsh (1998) suggested nine principles as the basic characteristics of TSM. A strategically based approach is proposed to underpin the totality of the company and presumably the vessel, ${ }^{25}$ adopting an operational, rather than a social, strategy with performance orientation of both employees and the company. Next, one has to deal with the executive commitment, not only from top, but also from everyone. One may easily talk here about teamwork on board, but given the anti-team character of Greek people much work and training must take place here, together with the establishment of a 'safety culture' (see above). People's behaviour may have to change for TSM (Weinstein, 1996; Rine, 1994), at least on board, and a strong commitment at the top (Karuppan et al., 1996) and leadership (Ansari, 1997) are required (Pun and Hui, 2002; Manuele, 1993). To paraphrase Ezell (1996), 'safety' is the adjective; 'management' is the subject. According to Deming (1986), top management is responsible for $94 \%$ of the problems because it controls the assignment of resources, establishes and implements the methods of work and develops policies. The most commonly observed approach to accidents, i.e., the 'blame the victim' approach, has to be avoided. In the case of accidents, in general, and marine accidents, in particular, however, we need to look even deeper (SIGTTO, 2001; Weick and Sutcliffe, 2001; Reason, 1997; Strauch, 2002, 2004).

Our theory stresses the fact that in ISM we encounter the principle that commitment must come from the top (as mentioned above). But, in shipping, commitment must be double: commitment from the top (Office) and commitment on board (from the Master). 
How is the former achieved in practice today? By a mere statement in the Safety manual-like: "the company ... is committed to safety and environmental protection". 27 This statement is then approved by the Managing Director. In such a case, the necessary commitment from the board of directors or the general assembly of the company is missing. Courts, no doubt, will look for responsibilities higher than the Managing Director (Goulielmos-Goulielmos, 2005) as they have done in the past.

Moreover, a commitment from Captain is required too. It is written that the Master "has the overriding authority and the responsibility to make decisions for safety and pollution prevention". In Figure 3, it is clear that the company must establish clear lines of responsibility ... with the Master ... and as shown in Figure 4, we consider that the key person involved is the Master and we show here what the ISM Code requires from the Captain (Figure 4). But, what has really to be required is shown in Figure 5.

Figure 4 Master's responsibilities by ISM

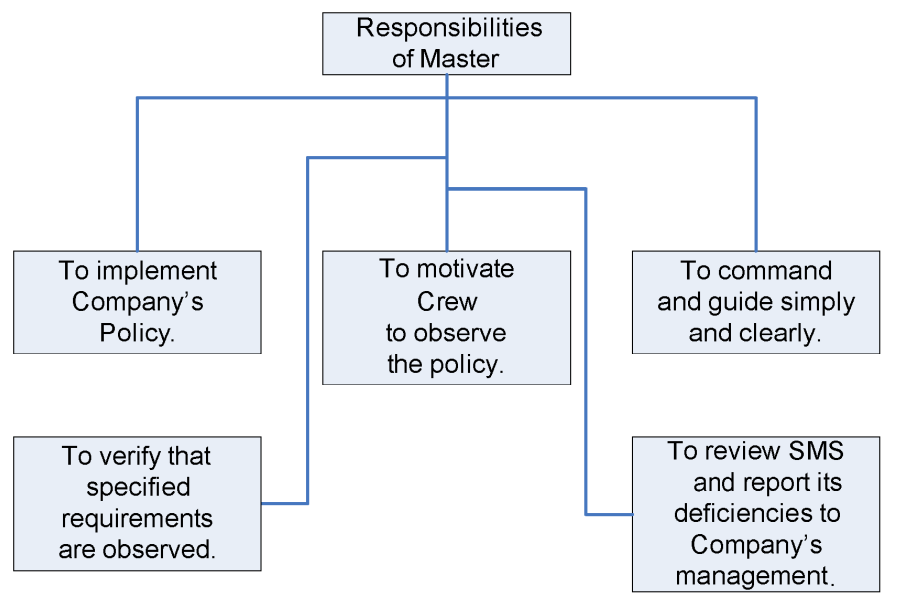

Figure 5 Informed culture for the captain

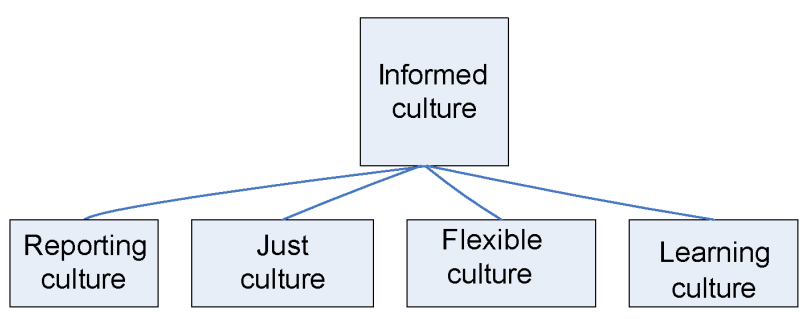

Source: Adapted from Reason (1998) and Weick and Sutcliffe (2001)

As shown in Figure 4, the Master, we believe, is the key person for safety on board and there is no doubt that safety depends on him. Thus, failure of safety must also be the responsibility of the Master. The company, as mentioned earlier, can avoid its responsibility by stating that he, the Master, is on board to decide all issues without question. And the Master is the one to ask the company for assistance, as he may think necessary. Here, we have not only clear lines of responsibility, but also, and more importantly, clear lines of cooperation have been established by the ISM. In Safety Manuals, a whole chapter is devoted to the Master, followed by 23 specific 
responsibilities, while he has to report to the DPA. The Master has 10 further responsibilities in relation to motivating the $\mathrm{Crew}$ and 7 more in monitoring the implementation of SMS.

Our proposal is that, instead of the above, shipping companies must establish an 'informed culture ${ }^{28}$ (Goulielmos, 2004, 2005, p.294) for the Captain, as shown in Figure 5.

Reporting culture ${ }^{29}$ (Weick and Sutcliffe, 2001) means ${ }^{30}$ what is to be reported when Captain (for the company) and crew (for the Captain) make errors or experience near misses. Just culture is how Company and Captain apportion blame when something goes wrong. Flexible culture means how readily the Captain (for the company) and crew (for the Captain) can adapt to sudden and radical increments in pressure, pacing and intensity. Learning culture means how adequately the Captain (for the company) and crew (for the Captain) can convert the lessons that they have learned into reconfigurations of assumptions, frameworks and actions. Lack of space prevents us from a further development of this theory.

\section{Our empirical research}

As Intertanko (2000) argued in the case of the Erika accident in 1999, the problem lies in the lack of adequate implementation of the existing body of international rules for tanker safety and pollution prevention. Intertanko's observations went beyond the mere concept of ship safety itself by highlighting the key links in the so-called 'chain of responsibility' (as well the transparency of substandard vessels): $\rightarrow$ ship owners $\rightarrow$ classification societies $\rightarrow$ charterers $\rightarrow$ flag states and $\rightarrow$ port states. This indeed creates a problem of asymmetry of cultures among 'safety links' when the end result depends on different safety partners. Do we have a safety culture (or standard) in all links of the safety chain? We do not, and this is most unfair for shipping. Shipping is a multifacet safety case, which includes 'Save and Rescue'. The latter, we think, is as important as safety.

As SIGTTO (2001, p.3) argued in the analysis of over 100 marine accidents, the acts are part of a complex casual network ... where human error is the most promising target for those that wish to reduce accidents, ${ }^{31}$ but first one must realise that there is risk. According to SIGTTO (2001), if we accept simple human error, we limit the causality from an eight stages process to two (p.4). As also put by $\operatorname{SIGTTO}^{32}$ (2001), accidents occur as a result of error, but in a very complex arrangement of causal nodes, to conveniently term them human is to miss the point and more importantly miss the opportunity to seek the root cause. ${ }^{33}$ This means that the ISM Code that focuses on human error is missing the point as well. As argued by one of the authors, marine accident statistics 'have' memory and certain sea areas 'attract' accidents like attractors where randomness has no place (Goulielmos, 2004).

Our empirical research covered 47 marine accidents that took place between 1 September, 2006 and 15 January, 2007. Our sample is representative of the relevant population as it covers $70 \%$ of all accidents that have occurred within the test period (5 months). The problem is that despite preventive measures and safety codes, marine accidents do occur. First, there is an inadequate approach to the reporting of marine accidents, as these are not classified between those due to human error and those due to technical error. 
As far as the age of ships is concerned, which can be considered a proxy for maintenance, the above accidents have shown that $40 \%$ were due to ships between 10 and 19 years of age (Figure 6). The fact that young ships are involved in marine accidents is a rather disturbing factor.

Figure 6 AGE of vessels in recent marine accidents, 2006-2007

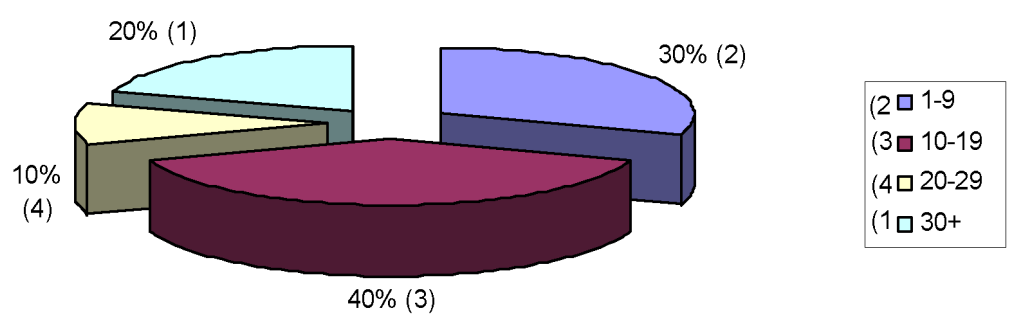

Source: Data from Lloyds

The causes of the accidents investigated indicate the failure of the ISM Code more clearly, as $41 \%$ of the marine accidents were due to collisions resulting from heavy weather as shown in Figure 7. Also 11\% were grounded.

Figure 7 Cause of accidents

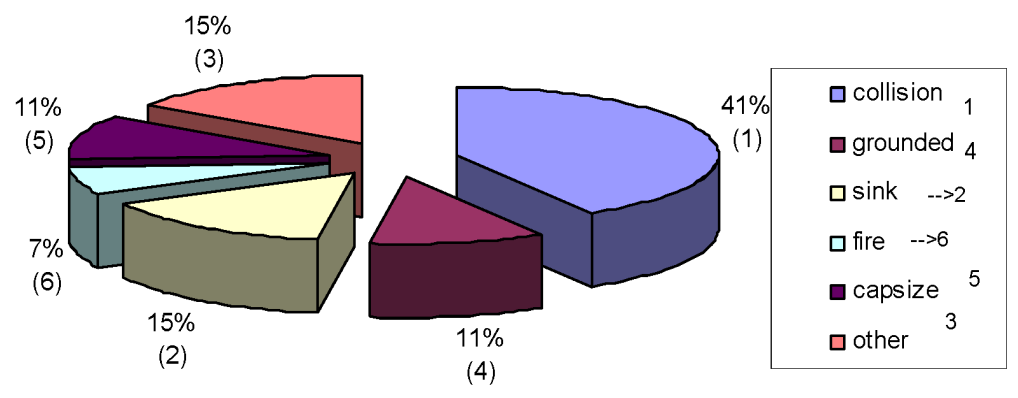

Source: Data from Lloyds

But, the failure of the ISM Code is also indicated by the losses involved in accidents - vessel loss, cargo loss and sea pollution together account for $51 \%$ of losses, as shown in Figure 8.

In relation to death and serious injury (Figure 9), unfortunately, the targets of the ISM Code have been missed completely, as $80 \%$ of people involved have died and $15 \%$ have been wounded. The largest single contribution came surely from the Indonesia accident at Bali, where 400 people were dead or missing. Research has shown that from the 50 or so recent marine accidents, in only 11 cases was it mentioned that ships have the required IMO and P + I Clubs certificates. In certain marine accidents, like the one with the 'Segesta Jet' at Messina, Sicily on 15 January, 2007 with 4 dead and 80 wounded, the safety of navigation failed and the two ships collided at the entrance of the port. Pollution has also occurred:

- on 23 September 2006 from the vessel 'Ginga Falcon' owing to human error, as the wrong tank has been overloaded

- from Tzini, on 25 December 2006 caused a pollution slick of $9 \mathrm{~km}$ in Taiwan. 
Figure 8 Marine accident outcomes

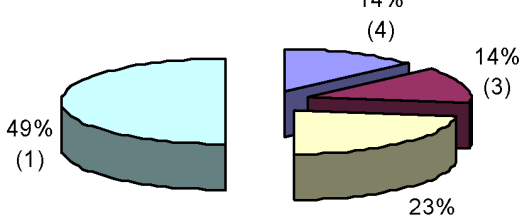

(2)

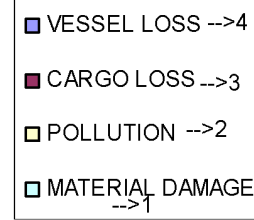

Source: Data from Lloyds

Figure 9 Loss of human life

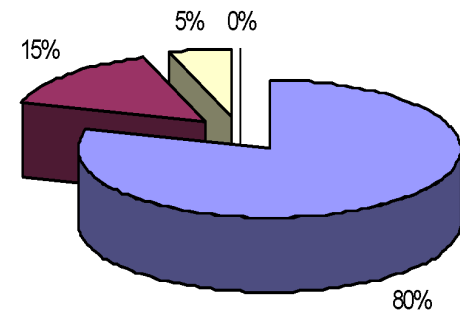

Source: Data from Lloyds

The lion's share to marine accidents belongs to dry cargoes $(29 \%)$ and to ships with relatively small sizes (50\% were from 15,000 to 19,999 GRT). So, despite the codes marine accidents continue to occur.

\section{Conclusions}

This paper has demonstrated that the TQM has to be put aside and TSM should be fully adopted in shipping. We have witnessed that the ISM Code, since 1998, has not been successful in stopping or curtailing marine accidents, even though it focused on human error, which had been neglected for the previous 250 years. Even so, it is now high time that the ISM Code be complemented - and in this paper we hope to have made a contribution in this direction. We have presented here the efforts of the OCIMF and SIGTTO to the same end. Our theory supports the idea that in shipping, feedback, commitment from the top, communications and motivation must change. The culture of the ship should be transformed from what it is today to a Safety Culture, and even more to an Informed Culture, a concept that was elaborated after Chernobyl accident. We have also suggested a change in management roles: the Captain should now be responsible for establishing a safety culture on board and it is his absolute responsibility and it is his commitment that counts and not that of the shore-based Management, which, in many cases, is used as an excuse for the Captain. Shore management acts from a distance - a distance of geographical complexity - and this has been so far overlooked. Although commitment from the top is required, it is not sufficient and cannot be effective alone, and responsibility on board must be established instead. A new term has been used appropriately in this paper $^{34}$ : mindfulness, which means to take care of safety or take thought for safety. If this is not done, codes, laws and papers are all useless. First, we must be mindful (about safety) to talk about safety. 


\section{Acknowledgements}

Thanks to an anonymous referee for valuable suggestions. Earlier version of this paper was presented in the IAME 2007 Athens Conference 4-6 July.

\section{References}

Algera, J.A. (1990) 'Feedback systems in organizations', in Cooper, C.L. and Robertson, I.T. (Eds.): International Review of Industrial and Organizational Psychology, J. Wiley \& Sons, Chichester, Vol. 5, pp.169-194.

Ansari, A. (1997) 'World-class strategies for safety: a boeing approach', International Journal of Operations and Production Management, Vol. 17, pp.389-398.

Atkinson, P.E. (1990) Creating Culture Change: The Key to Successful TQM, IFS Publications, Kempston.

Battram, A. (1998) Navigating Complexity: The Essential Guide to Complexity Theory in Business and Management, The Industrial Society, London.

Blair, E.H. (1996) 'Achieving a total safety paradigm through authentic caring and quality', Professional Safety, Vol. 41, No. 5, pp.24-27.

Botterill, M. (1991) 'Why you should implement TQ', Management Services, December, Vol. 2, pp.18-21.

Collard, R. (1989) Total Quality: A Success Through People, IPM, London.

Confederation of British Industry (CBI) (1990) Developing a Safety Culture-Business for Safety, CBI, London, UK.

Cooper, M.D. and Phillips, R.A. (1995) 'Killing two birds with one stone: achieving quality via total safety management', Leadership and Organizational Development Journal, Vol. 16, No. 8, pp.3-9.

Crosby, P.B. (1979) Quality is Free, McGraw-Hill, NY.

Dale, B.G. and Plunkett, J.J. (Eds.) (1990) Managing Quality, P. Allan, Hemel Hempstead.

Deming, W.E. (1986) Out of the Crisis, MIT, Cambridge MA, USA.

Drapkin, L. (1980) 'The right to refuse hazardous work after 'whirlpool', Industrial Relations Law Review, Vol. 14, pp.29-60.

Ezell, C.W. (1992) 'Safety management: A new and better way?', Occupational Hazards, Vol. 54, No. 10, pp.149-152.

Ezell, C.W. (1996) 'The pursuit of error-free performance', Occupational Hazards, Vol. 58, No. 6, pp.59-61.

Feigenbaum, A.V. (1983) Total Quality Control, 3rd ed., McGraw-Hill, NY.

Goetsh, D.L. (1998) Implementing Total Safety Management, Prentice-Hall, NY.

Goulielmos, A.M. (2002) 'Complexity theory applied to management of shipping companies', Maritime Policy and Management Int. Journal, Vol. 29, No. 4, pp.375-391.

Goulielmos, A.M. (2004) 'A treatise of randomness tested also in marine accidents', Intern. Journal of Disaster Prevention and Management, Vol. 13, No. 3, pp.208-217.

Goulielmos, A.M. (2004, 2005) Management of Shipping Companies, Vols. A \& B in Greek, A. Stamoulis editions, Athens, Piraeus, Greece.

Goulielmos, A.M. and Anastasakos, A. (2005) 'Worldwide security measures for shipping, seafarers and ports: an impact assessment of ISPS code', Intern. Journal of Disaster Prevention and Management, Vol. 14, No. 4, pp.462-478.

Goulielmos, A.M. and Giziakis, C.V. (2002) 'Marine accident prevention: an evaluation of the ISM Code by the fundamentals of the complexity theory', Disaster Prevention and Management an Int. Journal, Vol. 11, No. 1, pp.18-32. 
Goulielmos, A.M. and Giziakis, C.V. (2005) Quality Control in Shipping Companies and in the Ship, 3rd improved ed., Vol. A, Stamoulis, A. editions, Athens-Piraeus.

Goulielmos, A.M. and Goulielmos, M.A. (2005) 'The accident of MV herald of free enterprise: A failure of the ship or of the management?', Intern. Journal of Disaster Prevention and Management, Vol. 14, No. 4, pp.479-492.

Hackman, R.J. and Wageman, R. (1995) 'TQM: empirical, conceptual and practical issues', Administrative Science Quarterly, Vol. 40, pp.309-343.

Hellriegal, D., Slocum, J.W. and Woodman, R.W. (1989) Organizational Behavior, 5th ed., West, St. Paul, MN.

Hill, S. (1991) 'How do you manage a flexible firm?', The Total Quality Model, Work, Employment and Society, Vol. 5, pp.397-415.

Intertanko (9-13/4/2000) Briefing Notes. The Erika Accident and Issues Raised, Monte Carlo Tanker event, Monte Carlo, Monaco.

Juran, J.M. (Ed.) (1979) Quality Control Handbook, 3rd ed., McGraw-Hill, NY. He is considered with Deming the father of research in TQM.

Karuppan, C.M., Karuppan, M. and Schaefer, I.M. (1996) 'Total safety management: a TQM approach to industrial safety', Production and Inventory Management Journal, Vol. 37, No. 2 , pp.15-20.

Katz, D. and Kahn, R.L. (1966) The Social Psychology of Organizations, John Wiley, NY.

Kohn, L.T., Corrigan, J.M. and Donaldson, M.S. (Eds.) (1999) Err is Human: Building Safer Health System, National Academy Press, Washington DC.

Manuele, F.A. (1993) On the Practice of Safety, Van Nostrand Reinhold, New York.

Manzella, J.C. (1997) 'Achieving safety performance excellence through total quality management', Professional Safety, Vol. 42, No. 5, pp.26-28.

McMaster, M.D. (1996) The Intelligence Advantage: Organizing for Complexity, Butterworth, Heinemann.

Oakland, J. (1989) Total Quality Management, Heinemann, London, UK.

Oil Companies International Marine Forum (OCIMF) (2004) Tanker Management and Self Assessment (TMSA) Guide, London, UK.

Osborne, J. and Zairi, M. (1997) Total Quality Management and the Management of Health and Safety, Health and Safety Executive, London.

Pollock, R.A. (1995) 'Making safety matter', Occupational Hazards, Vol. 57, No. 10, pp.193-198.

Priesmeyer, H.R. (1992) Organizations and Chaos: Defining the Methods of Nonlinear Management, Quorum books, Westport, USA.

Pun, K.F. and Hui, I.K. (2002) 'Integrating safety dimension in quality management systems: a process model', Total Quality Management, Vol. 13, No. 3, pp.373-391.

Reason, J.T. (1997) Managing the Risks of Organizational Accidents, Aldershot, Hants, UK.

Reason, J.T. (1998) 'Achieving a safe culture: theory and practice', Work and Stress, Vol. 12, pp.293-306.

Rine, F. (1994) 'Safety and quality: the synonymous sisters for the 1990s', Safety and Health, Vol. 149, pp.63-67.

Schein, E.H. (1999) The Corporate Culture Survival Guide, Jossey-Bass, S. Francisco.

Seddon, J. (1989) 'A passion for quality', The TQM Magazine, May, pp.153-157.

Sitkin, S.B., Sutcliffe, K.M. and Schroeder, R. (1994) 'Distinguishing control from learning in TQM: a contingency perspective', Academy of Management Review, Vol. 18, pp.537-564.

Society of International Gas Tanker and Terminal Operators (SIGTTO) (2001) Society of International Gas Tanker and Terminal Operators, Human Error and the Environment: Management Systems for the Gas Industry, Witherby \& Co Ltd., London, UK. 
Strauch, B. (2002, 2004) Investigating Human Error: Incidents, Accidents, and Complex Systems, Ashgate, England.

Turner, B.A. and Pidgeon, N.F. (1997) Man-Made Disasters, 2nd ed., Oxford, Butterworth-Heinemann, UK.

Urrutia, B. (2006) 'The EU regulatory action in the shipping sector: a historical perspective', Maritime Economics and Logistics, Vol. 8, No. 2, June, pp.202-221.

Weick, K.E. and Sutcliffe, K.M. (2001) Managing the Unexpected: Assuring High Performance in an Age of Complexity, Un. of Michigan Business School Management Series, A Wiley Company, Jossey-Bass.

Weinstein, M.H. (1996) 'Improving safety programs through total quality', Occupational Hazards, Vol. 58, No. 8, pp.42-46.

Wilkinson, A. (1992) 'The other side of quality: 'soft' issues and the human resource dimension', TQM Journal, Vol. 3, No. 3, pp.323-329.

Wilkinson, A., Allen, P. and Snape, E. (1991) 'TQM and the management of labour', Employee Relations, Vol. 13, pp.24-31.

Williams, J.C. (1991) 'Safety cultures: their impact on quality, reliability, competitiveness, and profitability', in Matthews, R.H. (Ed.): Reliability 91, Elsevier, Amsterdam, The Netherlands.

\section{Notes}

${ }^{1}$ The US Coast Guard defines a marine accident as any casualty or accident involving a vessel (Strauch, 2002, 2004).

${ }^{2}$ Also in ABS, and other improvements in case of a collision and in relation to wheels, steering etc.

${ }^{3}$ The international management code for the safe operation of ships and for pollution prevention as adopted by the Assembly (and as may be amended) by the Organisation (International Maritime-IMO) as Chapter IX of SOLAS convention 1974 in force since 1 July, 1998 for certain types and sizes of ships. It has been amended on 1 July, 2002.

${ }^{4}$ Chapter XI-2 of Solas in force since 1 July, 2004 called: "International ship and port facility security code".

${ }^{5}$ Oil companies' international marine forum.

${ }^{6}$ Society of International Gas Tanker and Terminal Operators Ltd.

${ }^{7}$ ISPS code is a product of the events that took place in USA on 11 September, 2001.

${ }^{8} \mathrm{An}$ action or decision that results in one or more unintended negative outcomes (p.21) (Strauch, 2002, 2004).

${ }^{9}$ Deals with protection of crew members that report.

${ }^{10}$ This is called an observed situation where objective evidence indicates the non-fulfilment of a specified requirement.

${ }^{11}$ In the ISM Code, a major non-conformity is an identifiable deviation that poses a serious threat to the safety of personnel or the ship or a serious risk to the environment that requires immediate corrective action and includes the lack of effective and systematic implementation of a requirement. These have to be well pre-specified to make sense.

${ }^{12}$ A safety culture is an informed culture (Reason, 1997; Weick and Sutcliffe, 2001) where those who manage and operate the system have current knowledge about the human, technical, organisational and environmental factors that determine the safety of the system as a whole.

${ }^{13}$ A Designated Person Ashore is an office-officer liaison between ship and office and responsible for safety.

${ }^{14}$ Complaints must be perceived as positive feedback, where an improvement will follow. In the ISM Code, non-conformities and major non-conformities are negative feedback. Also according to Port State Control, we create a system of error-punishment philosophy. This philosophy does not build the so-called 'reporting culture' mentioned here. 
${ }^{15}$ Culture change is admittedly hard, slow and subject to frequent relapses and according to Schein (1999) is used when a specific problem is to be solved. Only when a work can be done with existing cultural strengths (Weick and Sutcliffe, 2001, p.125), culture change is not allowed to be exerted. We disagree with applying the same idea to ship's safety culture change, as safety culture change in shipping has an element of urgency and where enough time in ships is not available. See also Goulielmos (2004, 2005).

${ }^{16}$ One of the pioneers who stands out in the field of total quality.

${ }^{17}$ In the case of the accident of M/V RoRo 'Scandinavian Star' (1990), most passengers died as a result of suffocation from the gases released from the burning of the fire-resistant doors made from a new chemical substance probably not tested before!

${ }^{18}$ Indeed, this is a requirement of the ISM Code and characteristically enough frequently constitutes an observation made by external auditors (PSC).

${ }^{19} \mathrm{~A}$ reporting culture is about protection of people who report and what kind of report is trusted.

${ }^{20}$ Here, a safety culture must be developed against medical errors so that the processes and workforce have to be focused on improving the reliability and safety of care for patients.

${ }^{21}$ Which of course always has been there and even before the ISM Code.

${ }^{22}$ The forum believes that best practice is the most effective way to solve problems. It creates opportunities and it optimises the performance in the critical areas of safety and the absolute protection of the environment.

${ }^{23}$ See www.ocimf-tmsa.com (with a fee).

${ }^{24}$ Given that Oil Companies take care when they select ships for charter so that these ships need to be well maintained and well managed.

${ }^{25}$ This is more than checking off boxes by the First Mate.

${ }^{26}$ To achieve: a clear corporate mission, promote common values, foster and embed a strong safety culture to give a clear sense of direction to employees, establish guiding principles, recognise and reward safety efforts have active managerial participation in carrying out accident prevention programmes. They should lead the way to the accomplishment of company's goals, they should lead by example.

${ }^{27}$ From a company's Safety Manual.

${ }^{28}$ Exists in a vessel, if the Captain has current knowledge about human, technical, organisational and environmental factors, which determine the safety of the ship.

${ }^{29}$ Knowledge based on personal experience is questioned if this is the most trusted source of knowledge. Also, the next most trusted source of knowledge is oral communication.

${ }^{30}$ Violation of informed culture took place during the explosion on 7 August 1994, which killed 11 miners in Australia (Moura underground coal mine) (Weick and Sutcliffe, 2001, p.128).

${ }^{31}$ And it was here that ISM Code was successful, i.e., to deal with human error, a field ignored for 250 years.

${ }^{32}$ Prepared also to resort to a guide to self-assessment like OCIMF.

${ }^{33}$ One must condemn the statement of Ivar Manum, Managing director of the Norwegian Maritime Directorate, in case of high-speed ferry 'Sleipner' with a loss of 16 lives: "accidents must occur for safety at sea to improve"...

${ }^{34}$ Taken from University of Michigan Business School Management series (Weick and Sutcliffe, 2001, p.128). 